\title{
Aprendizagem significativa: transformando a sala de aula em laboratório para o ensino de ciências
}

\section{Meaningful learning: transforming the classroom into a laboratory for science teaching}

\author{
Alana Rafaela Borsekowsky (alanaborsekowsky.biologia@gmail.com) \\ Instituto Federal Farroupilha
}

Cátia Keske (catia.keske@iffarroupilha.edu.br) Instituto Federal Farroupilha

Fabiana Lasta Beck Pires (fabiana.pires@iffarroupilha.edu.br) Instituto Federal Farroupilha

Felipe Ketzer (felipe.ketzer@iffarroupilha.edu.br) Instituto Federal Farroupilha

Sandra Elisabet Bazana Nonenmacher (sandraebn1964@gmail.com) Instituto Federal Farroupilha

Resumo: Este artigo resulta de uma experiência de Estágio Curricular Supervisionado do Curso de Licenciatura em Ciências Biológicas, voltado a uma turma de Educação de Jovens e Adultos (EJA), no Ensino Fundamental. Trata de uma vivência que procurou romper com métodos de ensino tradicionais, comumente utilizados nas aulas de Ciências da Natureza. Uma experiência amparada em diferentes metodologias, com ênfase na atividade prática, para desenvolver conceitos de Física e Astronomia. O objetivo principal foi articular os temas e desenvolver as aulas, tendo como pressuposto balizador a Teoria da Aprendizagem Significativa. Consequentemente, a avaliação também teve de ser revista, ao encontro da proposta metodológica das aulas. Os principais resultados apontam para um maior envolvimento dos estudantes, que com o rompimento das resistências iniciais provocadas pelas metodologias ativas, evidenciaram predisposição para a aprendizagem. Nesse contexto, evidencia-se que os pressupostos da Aprendizagem Significativa se adaptam à Educação de Jovens e Adultos, considerando suas premissas de trabalhar conceitos científicos relevantes para o cotidiano e de associá-los aos conhecimentos prévios dos estudantes, usando-os como ancoragem para os próximos.

Palavras-chave: conhecimento prévio; educação de jovens e adultos; ensino de física.

Abstract: This article is the result of a Supervised Curricular Internship experience of the Teaching Degree in Biological Sciences, focused on a class of Youth and Adult Education in Elementary School. It is an experience that attempted to break with traditional teaching methods commonly used in Nature Science classes. Support was sought in different methodologies, with emphasis on practical activity, to develop concepts in Physics and Astronomy. The main objectives were to articulate the topics and develop the classes based on the Theory of Meaningful Learning. Consequently, the

Recebido em: $30 / 04 / 2020$ 
evaluation method was also revised, following the methodological approach of the classes. The main results point to greater involvement of the students, breaking the initial resistances provided by the active methodologies, evidencing predisposition to learning. In this context, we understand that the conditions of Meaningful Learning are adapted to Youth and Adult Education, considering its principles of working on scientific concepts relevant to everyday life and associating them with the previous knowledge of the students, using them as anchorage for future learning.

Palavras-chave traduzidas: prior knowledge, youth and adult education, physics teaching

\section{INTRODUÇÃO}

A maioria dos conteúdos trabalhados em sala de aula são interessantes para os estudantes apenas no momento em que são apresentados e quando há alguma atividade em uma postura discente marcada pela perspectiva behaviorista, caindo no esquecimento logo em seguida. Além disso, comumente os docentes limitam-se, nas aulas, ao quadro negro, leitura e resolução de questões do livro didático, ignorando outras metodologias que podem contribuir de forma significativa para a aprendizagem, tais como a experimentação prática problematizadora. Sendo assim, como refere Mottin (2004, p. 13), "é necessário que os professores repensem a sua prática pedagógica, buscando novas alternativas de ensino e recursos adequados".

Para melhorar o ensino público brasileiro, essas barreiras podem ser rompidas, disponibilizando-se conhecimentos usuais que se somem aos saberes prévios dos estudantes. Eles possuem conhecimento sobre diversos assuntos "que podem ter sido construídos na escola ou nas demais atividades do seu cotidiano" (MENDONÇA, 2012, p. 15), sobre os quais sabem falar. Assim, é possível fugir do método expositivo dialogado em que há apenas a parte teórica e abstrata, transferida pelo professor, acrescentando aulas práticas que explorem recursos disponíveis ou construídos para o momento e estimulem a participação ativa dos estudantes.

Durante a observação de algumas aulas de Ciências, em uma turma de Educação de Jovens e Adultos (EJA) do Ensino Fundamental de uma escola estadual, a abordagem adotada pelo docente titular surpreendeu por utilizar as mesmas metodologias didáticas para vários conteúdos diferentes, resultando na desatenção e desinteresse da maioria dos estudantes. Essa postura docente ainda está presente em muitas salas de aula do Brasil, e muitos são os fatores que a determinam, entre eles a 
Edição Especial: XVI Encontro sobre Investigação na Escola - EIE

falta de investimento em materiais didáticos alternativos e de formação pedagógica qualificada para proporcionar metodologias diversas que auxiliem no aprendizado.

Diante dessa realidade, surgiu a ideia de inovar na maneira como os conteúdos eram apresentados para a turma, então, durante cerca de dois meses o tema Astronomia e alguns princípios básicos da Física, como Sistema Internacional de Medidas (S.I), Mecânica (cinemática: movimento retilíneo uniforme), Velocidade Média, Aceleração, Forças e Movimentos foram trabalhados com os estudantes, no estágio em Ciências do Ensino Fundamental, no Curso de Licenciatura em Ciências Biológicas. O objetivo principal foi articular os temas e desenvolver as aulas, utilizando como base a Teoria da Aprendizagem Significativa (MOREIRA, s.d.), pela qual o estudante articula novas informações com os saberes que já possui, melhorando a compreensão e significação dos conhecimentos compartilhados em sala. Nesse processo, os novos conhecimentos adquirem significado para o sujeito e aos prévios somam-se novos sentidos ou maior estabilidade cognitiva.

\section{CONTEXTO E DETALHAMENTO DAS ATIVIDADES}

Para entender como é o cotidiano escolar e como enfrentar desafios educacionais, foi disponibilizado pelo Instituto Federal Farroupilha Campus Panambi, na disciplina Estágio Curricular Supervisionado I e II, o contato presencial com uma turma de Educação de Jovens e Adultos (EJA) do Ensino Fundamental. Foram observados, durante o primeiro semestre de 2019, os métodos e metodologias de ensino utilizadas pelo docente regente e como a turma respondia a sua didática. Após algumas semanas em sala, enquanto aconteciam as aulas de Ciências, pode-se observar que as atividades e métodos avaliativos eram maçantes e não instigavam os estudantes na busca pelo conhecimento.

Essas observações foram utilizadas no segundo semestre, quando foi desenvolvido um trabalho de regência, que teve como objetivo melhorar o ensino e também a aprendizagem da turma, com novas propostas de aulas que atendessem às necessidades de todos. No decorrer de alguns meses, vários métodos didáticos e avaliativos foram desenvolvidos com a classe, a fim de melhorar a sua relação com as Ciências, tendo o enfoque de conteúdos de Física e Astronomia. Entre as atividades utilizadas estavam seminários, trabalhos com pesquisas na Internet, resumos das aulas, relatos com desenhos, aulas práticas com materiais disponíveis na sala de aula,

Recebido em: $30 / 04 / 2020$

Aceito em: $19 / 11 / 2020$ 
Edição Especial: XVI Encontro sobre Investigação na Escola - EIE

observação estelar e rodas de conversa.

Com essas duas vivências em uma mesma turma, o que se destacou foi a necessidade de promover um ensino significativo que atendesse a todos os indivíduos presentes na sala de aula. Para isso, pesquisas bibliográficas sobre a Aprendizagem Significativa, articuladas com discussões sobre o ensino na EJA, antecederam o planejamento e a vivência do estágio.

\section{TRANSFORMANDO A SALA DE AULA EM LABORATÓRIO DE FÍSICA}

Durante o segundo semestre letivo de 2019 foram desenvolvidas aulas com conceitos de Física e Astronomia, tendo como proposta metodológica a articulação dos temas. A turma nunca havia tido contato com esses conteúdos, precisando começar por conceitos básicos evoluindo até aquele planejado para as aulas.

O desenvolvimento do conteúdo iniciou-se com uma explicação expositiva dialogada sobre o Sistema Internacional de Medidas (S.I). Para demonstrar que era algo do cotidiano de todos, foram levados alguns exemplos de utilização das diferentes unidades de medida, tais como: fita métrica, régua, além de materiais escolares, a fim de enfatizar qual unidade de medida seria utilizada para medir a massa do objeto ou a altura. A segunda aula foi voltada para o ensino de Astronomia, tendo a Lua como foco. Os educandos tiveram uma aula prática para observá-la e após debater sobre as suas fases, na sala, com atividades sobre o tema.

A terceira aula foi dedicada à Mecânica (cinemática), na qual o espaço da sala de aula foi explorado para a explicação da ideia de Referencial e Movimento Retilíneo Uniforme. Velocidade Média, Velocidade Instantânea, Aceleração, Força, Inércia e Gravitação foram conceitos/temas trabalhados durante os encontros seguintes, articulando conhecimentos do cotidiano dos estudantes com os científicos e astronômicos. A proposta que se seguiu durante as aulas foi a de abordar e relacionar os saberes inicialmente significados em sala com uma visão sobre os Planetas do Sistema Solar e suas especificidades. Para auxiliar a compreensão visual e estimular o interesse pelo tema, um planetário móvel foi criado e levado para a aula (Figura 1). 


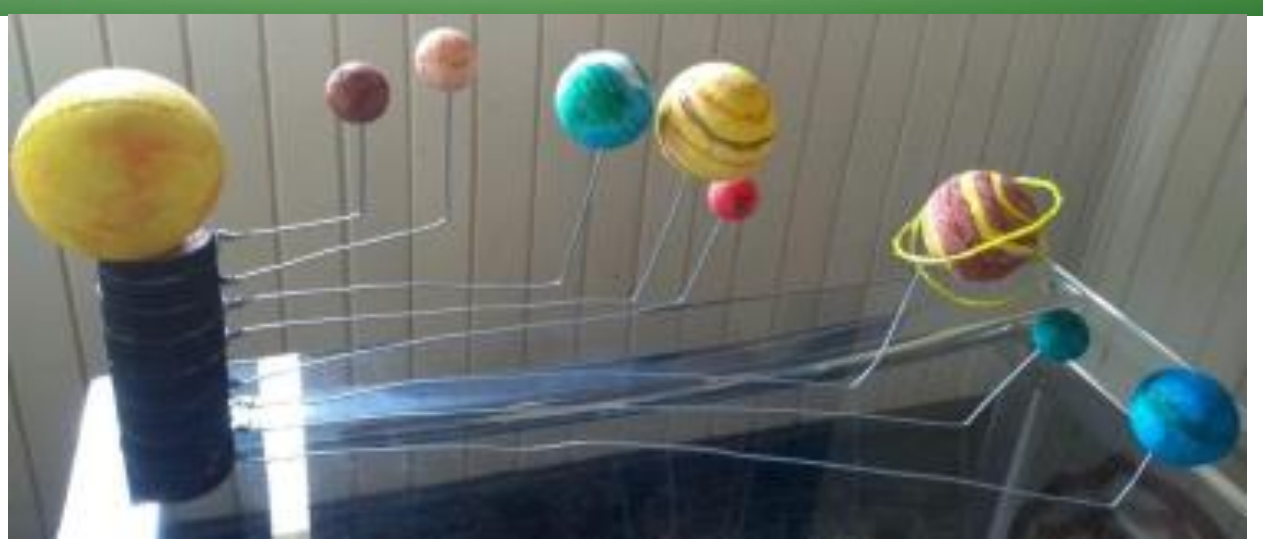

Figura 1 - Planetário Móvel

O planetário foi construído com material de baixo custo pela estagiária e teve o objetivo de possibilitar a compreensão do sistema solar, retomar os conceitos de gravitação e de dados astronômicos. Considerou-se Langhi e Nardi (2009), que ao analisarem dados sobre o ensino de astronomia no Brasil, questionam por que continua sendo um saber repleto de concepções espontâneas, erros conceituais, mitos e dificuldades no processo de ensino e aprendizagem, mesmo diante de uma ampla gama de informações dessa natureza disponível na atualidade. Para os autores, as hipóteses mais prováveis são de que:

\begin{abstract}
a) há pouco interesse da população e dos alunos em aprender astronomia; b) uma quantidade insuficiente de estabelecimentos para atender a demanda de educação em astronomia; c) há pouco interesse das associações amadoras, observatórios e planetários em se envolver com a educação em astronomia, optando por contemplar principalmente atividades de popularização, educação não formal, ou mesmo informal, na base do senso comum (LANGHI; NARDI, 2009, p.7).
\end{abstract}

Diante dessas hipóteses, cabe ao professor proporcionar atividades que priorizem a sistematização dos conhecimentos científicos relacionados à Astronomia e utilizar recursos didáticos que estimulem a participação e a motivação do estudante em querer conhecer mais, para além do senso comum.

Além da proposta de desenvolver atividades práticas, houve também a preocupação de utilizar diferentes instrumentos avaliativos, tanto para analisar a compreensão inicial dos estudantes quanto para acompanhar o processo de aprendizagem. Para tanto, foram utilizadas atividades de escrita de síntese e relatório, seminário, debate, trabalho em grupo, construção de experimentos e exploração do espaço. Vale destacar que esse "cuidado" - para além de ser premissa anterior ao início da regência - foi ratificado após o indicativo da vivência de episódios de ansiedade, 
Edição Especial: XVI Encontro sobre Investigação na Escola - EIE

ISSN: 2595-4520 Vol. 4, n. 2. 2021

desencadeados por "provas" e "testes", conforme relatado por parte de alguns alunos.

Some-se a isso a complexidade de alguns conceitos físicos, pois como enfatizam

Vasconcelos e Leão (2016), ao destacarem que muitos estudantes não conseguem associar o conhecimento científico com os acontecimentos cotidianos, é um desafio tornar o ensino de Física prazeroso e instigante, que seja capaz de desenvolver a educação científica.

\section{ANÁLISE E DISCUSSÃO DO RELATO}

Componentes curriculares como Física, Matemática e Química têm fama de difíceis, produzindo aversão nos primeiros contatos escolares, sendo uma das últimas opções de escolha para formação e profissão futura. Isso talvez aconteça pelas práticas nas quais a aprendizagem memorística é tida como única possibilidade (TAVARES, 2004) ou porque ainda se trabalha com algo abstrato distante do cotidiano do indivíduo. "Em raras situações são explicitadas considerações, de modo a permitir aos aprendentes uma visão mais clara do mundo que os cerca" (ibidem, p. 57), o que prejudica o estabelecimento de relações com o que está sendo estudado.

Para Lunetta (1991, apud LEITE; SILVA; VAZ, 2008, p. 168) “as aulas práticas podem ajudar no desenvolvimento de conceitos científicos, além de permitir que os estudantes aprendam como abordar objetivamente o seu mundo e como desenvolver soluções para problemas complexos." Assim, utilizando aulas experimentais para explicar conceitos da Física e de Astronomia pode-se perceber que os estudantes tinham dificuldades quando lhes era apresentada apenas a parte teórica, abstrata e matematizada:

\footnotetext{
A física é a ciência que explica o que ocorre na natureza, então parece imediato partir de experiências para ensinar este princípio. Realmente, a partir de situações criadas num laboratório didático, é possível mostrar aos estudantes que, eliminando forças resistivas, um objeto não perde velocidade e pode continuar seu movimento indefinidamente [...] (INHELDER; PIAGET, 1976).
}

Durante o período de estágio, procurou-se trabalhar ao encontro de "um laboratório didático", focando a melhora no entendimento de conceitos de Física no cotidiano de cada um dos alunos e em conceitos de Astronomia. Quando a turma foi apresentada à ideia de estudar a Lua e os Planetas, com suas acelerações e características individuais, não entendeu o motivo e a importância disso, mas conforme o aprofundamento nos conceitos acontecia, aproximou-se do defendido por Dias e Santa

Recebido em: 30 /04/ 2020

18

Aceito em: 19/11/2020 
Rita:

O ensino de Astronomia é importante principalmente para estabelecer uma relação entre o aluno e a dinâmica do universo, conhecimentos essenciais como os modelos de evolução cósmica, os movimentos da Terra e de outros astros, a estrutura das estrelas, a comparação entre os planetas do sistema solar, a possibilidade de detecção de outros planetas em outros sistemas estelares, além de outros assuntos (DIAS; SANTA RITA, 2008, p. 61).

Apesar de certa resistência inicial às mudanças metodológicas, inclusive quanto aos instrumentos avaliativos, a turma demonstrou compreensão dos assuntos trabalhados. Além do significado conceitual científico entendeu suas implicações no cotidiano e como tais conhecimentos permitem compreender melhor o mundo no qual vive e interage.

Práticas pedagógicas como a relatada neste texto evidenciam a importância dos professores conhecerem as condições para favorecer a aprendizagem significativa em sala de aula, ainda na formação inicial, como defendem Silva e Braibante (2018). Ademais, recomendam a participação de licenciandos em pesquisas e elaboração de metodologias didáticas que sirvam como estratégia de ensino, nas quais sejam participantes e construam ativamente seu conhecimento. Segundo as autoras, tal conhecimento possibilita "a identificação e utilização das ideias prévias para o planejamento de aulas e elaboração de atividades didáticas (materiais potencialmente significativos) [...] coerentes com as estruturas cognitivas dos estudantes" (SILVA; BRAIBANTE, 2018, p. 19), o que fortalece concepções pedagógicas e didáticas de forma teórica e prática.

Nessa postura didático-pedagógica, o uso de atividades experimentais não basta, não assegura, por si só, aprendizagens significativas. Conforme Luca, Santos, Del Pino e Pizatto (2018), não é suficiente propor um experimento, sendo a forma de condução e as abordagens propiciadas durante a realização da atividade (questionamentos, discussões e reflexões fomentadas) determinantes para uma proposta eficaz no ensino.

Para além disso, no contexto dessa vivência pedagógica, a aula prática funcionou como ferramenta para despertar o interesse dos jovens e adultos pelo ensino de Física, pois gerou curiosidade e um sentimento de satisfação. Nesse sentido, foi ao encontro do que destacam Leite, Silva e Vaz (2008), sem necessariamente fazê-la utilizando exclusivamente o laboratório, desmistificando-o como espaço único para experimentações no ensino de Ciências da Natureza. Nisso reside a importância de os 
professores visualizarem a sala de aula como laboratório.

\section{CONSIDERAÇÕES FINAIS}

O desenvolvimento de uma prática pedagógica pautada pelas premissas da Aprendizagem Significativa em uma turma de EJA permitiu a compreensão sobre a potencialidade de atividades experimentais para a ampliação e reconfiguração de conceitos anteriores. Nesse contexto, compreendemos que a teoria da Aprendizagem Significativa se adequa muito bem à Educação de Jovens e Adultos, já que tem como uma das suas premissas trabalhar conceitos científicos relevantes para o cotidiano e associá-los aos conhecimentos prévios dos estudantes, usando-os como ancoragem para os próximos. Mesmo que neste trabalho não estejam explicitados de forma textual os conceitos prévios e os novos que foram explorados, o desenrolar das aulas e das produções dos estudantes tinha um olhar atento da estagiária para com eles.

Trabalhando em uma turma de EJA de uma escola pública estadual, pode-se observar algumas dificuldades pelas quais passam professores e alunos da modalidade, pois não há como não referir o contexto de políticas públicas que ora fragilizam ora tentam fortalecer a modalidade. Reconhecer e dispor-se a compreender fragilidades de infraestrutura, de falta de valorização dos profissionais da educação e de inflexão curricular, como a tencionada recentemente pela Base Nacional Curricular Comum (BNCC), leva à visualização de marcas das dimensões político-econômica e sociocultural da EJA. Porém, se reconhece que há a possibilidade de desenvolver atividades práticas problematizadoras sem que sejam necessários grandes laboratórios, com equipamentos sofisticados. A sala de aula e os materiais do cotidiano se configuram em ótimos aliados dos professores.

Por outro lado, ratificou-se a importância da forma de abordar os conteúdos e das opções metodológicas por parte do professor. Essa afirmação é subsidiada na postura de participação e envolvimento dos estudantes durante as aulas no período da prática aqui relatada. Além disso, a análise de uma prática profissional de estágio supervisionado em curso de licenciatura, fundamentada com elementos da Teoria da Aprendizagem Significativa de Ausubel, evidencia uma reconfiguração curricular quando o estudante acompanha a demanda dos conteúdos que são planejados. 
Edição Especial: XVI Encontro sobre Investigação na Escola - EIE

ISSN: 2595- $4520 \quad$ Vol. 4, n. 2. 2021

Acrescenta-se a isso, o fato de que à medida que o estudante constrói nova compreensão para a sua vida, por novos conceitos científicos incorporados aos seus conhecimentos prévios, compreende a importância da formação escolar, o que pode contribuir para diminuir a evasão escolar na EJA.

6.

\section{REFERÊNCIAS}

DIAS, C. A. C. M.; SANTA RITA, J. R. Inserção da astronomia como disciplina curricular no ensino médio. Revista Latino-Americana de Educação em Astronomia - RELEA, n. 6, p. 55-65, 2008.

INHELDER, B.; PIAGET, J. Da lógica da criança à lógica do adolescente. Tradução por Dante Moreira Leite. São Paulo: Pioneira, 1976.

LANGHI, R.; NARDI, R. Ensino de astronomia no Brasil: educação formal, informal, não formal e divulgação científica. Revista Brasileira de Ensino de Física, v. 31, n. 4, p. 4402-1 - 4402-11, 2009.

LEITE, A. C. S.; SILVA, P. A. B.; VAZ, A. C. R. A importância das aulas práticas para alunos jovens e adultos: uma abordagem investigativa sobre a percepção dos alunos do PROEF II. Revista Ensaio, Belo Horizonte, v. 03, n. 7, p. 166-181, 2005 .

LUCA, A. G.; SANTOS, S. A.; DEL PINO, J. C.; PIZATTO, M. C. Experimentação contextualizada e interdisciplinar: uma proposta para o ensino de ciências. Revista Insignare Scientia. Chapecó/SC, vol. 1, n. 2. mai./ago. 2018.

MENDONÇA, C. A.S. Investigando conhecimentos dos licenciandos em biologia sobre aprendizagem significativa. Aprendizagem Significativa em Revista, Porto Alegre, 2012, v. 2, n. 3, p. 14-24. Disponível em:

http://www.if.ufrgs.br/asr/artigos/Artigo_ID34/v2_n3_a2012.pdf. Acesso em: 10 fev. 2020.

MOREIRA, M. A. O que é afinal aprendizagem significativa? Disponível em: www.if.ufrgs.br./ moreira. Acesso: $10 \mathrm{de}$ fev. 2020.

MOTTIN, Elisandra. A utilização de material didático-pedagógico em ateliês de matemática, para o estudo do teorema de Pitágoras. 2004. 117 f. Dissertação (Mestrado em Ciências e Matemática) - Pontifícia Universidade Católica do Rio Grande do Sul, Porto Alegre, 2004.

SILVA, J. A. S.; BRAIBANTE, M. E. F. Aprendizagem significativa: concepções na formação inicial de professores de ciências. Revista Insignare Scientia. Chapecó/SC, vol. 1, n. 1. jan./abr. 2018.

Recebido em: $30 / 04 / 2020$

Aceito em: 19/11/2020 
Edição Especial: XVI Encontro sobre Investigação na Escola - EIE

TAVARES, R. Aprendizagem significativa. Revista Conceitos, p. 55-60, jul. 2003/jun. 2004.

VASCONCELOS, C. O. L.; LEÃO, Marcelo F. Uso de simulações digitais e demonstrações experimentais como ferramentas para ensinar cinemática na educação de jovens e adultos. In: Mostra de Trabalhos dos Cursos de Especialização do IFMT Campus Confresa, 1, 2016. Confresa - MT. Anais [...]. Confresa, MT: Instituto Federal de Mato Grosso, 2016. v. 1. p. 18-22.

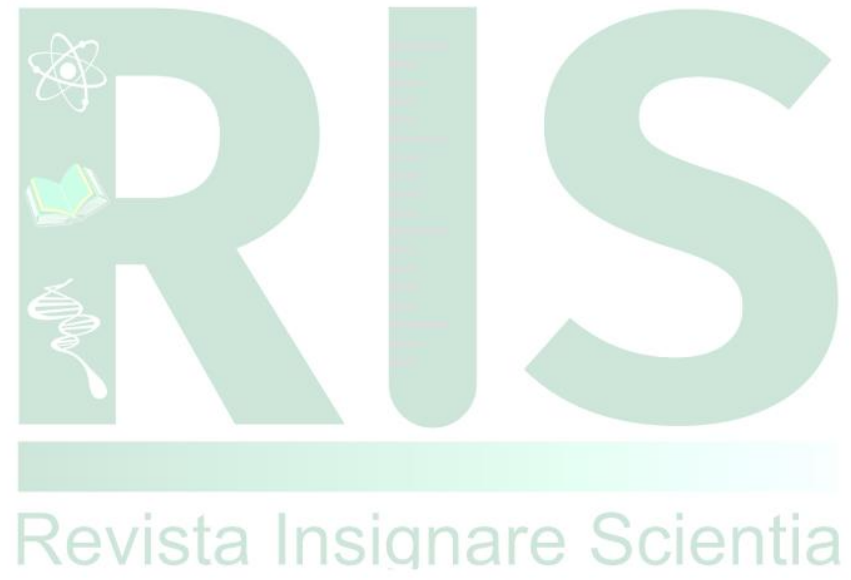

